\title{
A UTILIZAÇÃO DO ANTI-CD3 BUTANTAN NO TRANSPLANTE RENAL
}

\author{
Use of the Butantan's anti-CD3 in renal transplantation
}

\author{
Francine Lemos', Ana Maria Moro², Maria Teresa Alves Rodrigues², Angélica Garbuio², Sandra Maria Monteiro ${ }^{3,6}$, \\ Flavio Marques', Maria Cristina Ribeiro Castro', Luiz Estevam lanhez ${ }^{1}$, Jose Osmar Medina Pestana ${ }^{4}$, Valter Duro Garcia ${ }^{5}$, \\ Jorge Neumann ${ }^{5}$, Verônica Coelho ${ }^{3,6}$, Isaias Raw², Jorge Kalili,6
}

\begin{abstract}
RESUMO
Objetivos: $\mathrm{O}$ anticorpo monoclonal anti-CD3 tem sido empregado na prevenção e tratamento de episódios de rejeição aguda em transplante de órgãos. Neste estudo retrospectivo, relatamos a experiência de três instituições brasileiras que utilizaram o anticorpo anti-CD3 produzido pelo Instituto Butantan (São Paulo, Brasil) em pacientes transplantados renais. Métodos: Foram analisados 25 pacientes que receberam anti-CD3 para profilaxia $(n=9)$ e tratamento de rejeição celular aguda $(n=16)$. Resultados: Os pacientes que utilizaram o antiCD3 profilaticamente eram sensibilizados em sua maioria (89\%) e apresentaram ocorrência de rejeição aguda em $33 \%$ dos casos. O uso terapêutico foi indicado para tratamento de rejeição córtico-resistente ou rejeições de maior severidade histológica, e reverteu clinicamente $69 \%$ dos episódios tratados. Na maioria dos pacientes, o uso do anti-CD3 Butantan reduziu o número de células CD3+ a valores menores que $30 \mathrm{cel} / \mathrm{mm}^{3}$ no segundo dia de tratamento. O evento adverso mais freqüentemente observado foi febre e infecções bacterianas e virais, seis meses após o tratamento, que foram observadas em 13 e 10 pacientes, respectivamente. No período médio de seguimento de oito anos nenhuma ocorrência de tumor foi relatada. Conclusões: Concluímos que a utilização do anti-CD3 Butantan mostrou-se eficaz na profilaxia e tratamento de rejeição aguda em pacientes transplantados renais.
\end{abstract}

Descritores: Muromonab-CD3, Transplante de Rim, Imunossupressão, Rejeição de Enxerto

Instituições:

1. Unidade de Transplante Renal-Hospital das Clínicas da Faculdade de Medicina da USP, São Paulo

2. Laboratório de Biofármacos em Célula Animal - Instituto Butantan

3. Laboratório de Imunologia do Instituto do Coração - Hospital das Clínicas da Faculdade de Medicina da USP

4. Universidade Federal de São Paulo, Hospital São Paulo e Hospital do Rim e Hipertensão, São Paulo

5. Santa Casa de Misericórdia de Porto Alegre, Rio Grande do Sul

6. III - Instituto de Investigação em Imunologia, Institutos do Milênio, CNPq/MCT

Agências Financiadoras: Fundação Butantan e FINEP - Financiadora de Estudos e Projetos, projeto nº 01.04.0375.00 coordenado por Ana Maria Moro

\section{Correspondência:}

Jorge Kalil

Laboratório de Imunologia, Instituto do Coração

Av Dr Enéas de Carvalho Aguiar 44, $9^{\circ}$ andar

CEP 05403-001 São Paulo SP

Tel: 5511 3069-5900 Fax: 5511 3069-5953

E-mail: jkalil@usp.br

Recebido em: 03.09.2006

Aceito em: 05.10.2006

\section{INTRODUÇÃO}

A ativação e proliferação linfocitária são eventos centrais no processo de rejeição ao enxerto em transplante de órgãos. O primeiro dos três sinais necessários à ativação linfocitária é resultante da interação do complexo do receptor da célula T (TCR) e suas subunidades CD3, CD4/CD8 com o antígeno apresentado pelas células apresentadoras de antígeno. Um dos agentes biológicos utilizados como imunossupressor é o anticorpo monoclonal anti$\mathrm{CD} 3$, que reconhece o epítopo CD3 na superfície dos linfócitos $\mathrm{T}$ e pode inibir suas funções efetoras ao modular o complexo CD3/ TCR. Como resultado dessa modulação, os linfócitos T deixam de reconhecer as células alogeneicas presentes no enxerto, e assim bloqueiam a rejeição do tipo celular. Imediatamente após sua injeção, o anticorpo monoclonal anti-CD3 depleta as células T circulantes, o que pode ser verificado através da monitoração do percentual de células CD3 positivas em sangue periférico.

A tecnologia de geração de anticorpos monoclonais através da imortalização de clones de linfócitos B representou uma ferramenta poderosa para obtenção de grandes quantidades de anticorpos únicos e específicos e permitiu sua aplicação tanto em pesquisa como na prática clínica. ${ }^{1} \mathrm{O}$ primeiro anticorpo monoclonal anti-CD3 produzido comercialmente foi o OKT3, no início dos anos $80 .^{2}$

Desde o final dos anos 80 , o Instituto Butantan, em parceria com o Laboratório de Imunologia do Incor-HCFMUSP, vem dedicando esforços na produção de agentes biológicos imunossupressores. 
O primeiro agente biológico produzido foi a globulina antitimocitária Butantan, que se mostrou eficaz na reversão de episódios de rejeição aguda em pacientes transplantados renais. ${ }^{3}$ Nos últimos anos, o Instituto Butantan ampliou esses esforços para a produção do anticorpo monoclonal anti-CD3. No presente estudo, apresentamos uma análise retrospectiva do uso clínico do anti-CD3 Butantan em pacientes transplantados renais em três instituições brasileiras.

\section{MATERIAL E MÉTODOS}

\section{Pacientes}

Trata-se de uma análise retrospectiva de 25 pacientes submetidos a transplante renal que receberam anti-CD3 Butantan com indicação profilática como terapia de indução no início do transplante, ou no tratamento de episódios de rejeição aguda. Foram avaliados pacientes transplantados em três instituições: quatro pacientes transplantados no Hospital das Clínicas da Faculdade de Medicina da Universidade de São Paulo - HCFMUSP, 19 pacientes transplantados no Hospital do Rim e Hipertensão da Universidade Federal de São Paulo - UNIFESP e dois pacientes transplantados na Santa Casa de Misericórdia de Porto Alegre. Os pacientes do HCFMUSP e da UNIFESP que receberam o anti-CD3 Butantan foram transplantados no período de 1993 a 1998, e os pacientes da Santa Casa de Misericórdia de Porto Alegre no ano de 2001. Os dados foram obtidos após revisão do prontuário médico por um nefrologista de cada instituição e a última data de seguimento foi maio de 2006.

\section{Anti-CD3 Butantan}

A tecnologia de geração de anticorpos monoclonais através da imortalização de clones de linfócitos B representa uma ferramenta poderosa para obtenção de grandes quantidades de anticorpos únicos e específicos, os anticorpos monoclonais, ${ }^{1}$ permitindo sua aplicação em pesquisa e na clínica médica. $\mathrm{O}$ anticorpo anti-CD3, objeto deste estudo, pertence à subclasse $\operatorname{IgG}_{2 \mathrm{a}}$ e reconhece o epítopo CD3 na superfície dos linfócitos $\mathrm{T}$, podendo inibir suas funções efetoras ao modular o complexo CD3/TCR. Como resultado dessa modulação, os linfócitos $\mathrm{T}$ deixam de reconhecer células alogeneicas presentes no enxerto, e assim controlar a rejeição do tipo celular.

$\mathrm{O}$ anticorpo monoclonal anti-CD3 utilizado neste estudo clínico foi obtido pelo cultivo do hibridoma in vitro em biorreator de leito empacotado com aeração interna. ${ }^{4}$ Em resumo, uma ampola do Banco de Células foi descongelada e as células cultivadas em meio DME ou HSFM (Gibco, Invitrogen) em frasco spinner até obter aproximadamente $10^{9}$ células, que foram inoculadas no biorreator com volume de trabalho de $3 \mathrm{~L}$. As células cresceram sobre pequenos cilindros ocos de vidro dentro da dorna, criando uma situação de leito empacotado. Em sistema de perfusão contínua, as células imobilizadas atingiram alta densidade. Os cultivos foram monitorados on-line para temperatura, $\mathrm{pH}$ e oxigênio dissolvido pelo intermédio de sensores inseridos na tampa do biorreator. Amostras retiradas diariamente foram utilizadas para monitoramento metabólico (glicose, lactato, amônia) e da produtividade do antiCD3 por ensaio de ELISA. A velocidade da perfusão do meio de cultura foi calculada com base nos resultados dos parâmetros metabólicos, de maneira a manter um estado quase homogêneo. Os sobrenadantes dos cultivos foram processados por cromatografia de troca iônica e de afinidade em proteína A, seguido de diálise para acondicionamento em tampão de ampolamento.
Os métodos analíticos utilizados para controle de processo e controle do produto acabado consistiram de quantificação da proteína total pelo método de Lowry, eletroforese em gel de poliacrilamida em condições reduzidas e não reduzidas, determinação do ponto isoelétrico, quantificação do anticorpo monoclonal por ELISA, isotipagem do anti-CD3, teste de ausência de micoplasma no hibridoma por dois métodos, direto e kit colorimétrico, determinação de DNA residual, determinação de presença de agregados no produto final, teste de esterilidade microbiana e fúngica no granel e no produto acabado, teste de inocuidade em animais (cobaias e camundongos) no granel e no produto acabado, teste de pirogênio in vivo e in vitro, teste de microtoxicidade e imunofluorescência utilizando células humanas, determinação de concentração de cloreto e determinação de $\mathrm{pH}$. A ausência de vírus adventícios foi verificada por ensaios, onde as células do hibridoma e o produto final (anti-CD3 purificado) eram incubados com linhagens de células indicadoras da presença de vírus (uma linhagem derivada de macaco verde, uma linhagem derivada de macaco Rhesus, uma linhagem derivada de camundongo, uma linhagem derivada de hamster, duas linhagens de células humanas), utilizando como controle positivo o vírus da encefalomiocardite murina, que apresenta efeito citopático nessas células. ${ }^{5}$

Para avaliar a potência do produto foi utilizada a citometria de fluxo contra células humanas, com células de diferentes indivíduos. As análises realizadas em produto final foram realizadas em comparação ao produto comercial OKT3 (orthoclone). Os resultados encontraram-se dentro dos especificados para produtos dessa natureza, conforme preconizado pelas agências regulatórias.$^{6-9} \mathrm{O}$ único resultado que ficou acima das especificações foi o teor residual de DNA; contudo, o mesmo se encontrava em fragmentos menores que 200 pares de bases, portanto menor que qualquer oncogene..$^{10}$ Cabe ressaltar que, posteriormente, o limite de DNA residual para biofármacos deixou de ser tão crítico. ${ }^{11}$

$\mathrm{O}$ produto foi formulado em solução salina tamponada com fosfato pH 7,0 contendo $0,02 \%$ de polisorbato e ampolado no Setor de Envase do Instituto Butantan em ampolas de $5 \mathrm{~mL}$ contendo $1 \mathrm{mg} / \mathrm{mL}$. Diferentes lotes foram utilizados neste ensaio clínico. As ampolas foram armazenadas em geladeira à temperatura de $4^{\circ} \mathrm{C}-8^{\circ} \mathrm{C}$.

Os lotes produzidos de anti-CD3 foram ensaiados in vitro pela técnica de citometria de fluxo, para avaliar sua capacidade em se ligar a linfócitos T humanos, em comparação ao OKT3 comercial (orthoclone). Foram comparadas as medianas de fluorescência e a porcentagem de células positivas. Foram utilizadas células mononucleares de sangue periférico de indivíduos sadios, com o mínimo de células de três indivíduos. As células foram obtidas por gradiente de Ficoll-Hypaque. ${ }^{12}$ As células foram incubadas com o anticorpo monoclonal anti-CD3 pelo tempo determinado, lavadas e novamente incubadas com anticorpo anti-IgG murina conjugado à fluoresceína. Após as lavagens, procedeu-se à aquisição e análise no citômetro de fluxo (FacsCalibur, BD). Os resultados foram expressos em mediana de fluorescência (mediana de fluorescência do anticorpo teste menos mediana de fluorescência do anticorpo controle negativo) e porcentagem de células positivas (porcentagem de células positivas do anticorpo teste menos porcentagem de células positivas do anticorpo controle negativo). $\mathrm{O}$ anticorpo monoclonal foi testado em diluições decrescentes de 1:100 a 1:125.000. A escolha do título final era dependente das curvas obtidas pelos dois parâmetros (mediana da fluorescência e porcentagem de células positivas) em relação às células de indivíduos diferentes. Nos testes realizados com os produtos ampolados (anti-CD3 Butantan) obteve-se resultados comparáveis ao produto comercial. 
A técnica de citometria de fluxo também foi utilizada para avaliar a eficiência in vivo do anti-CD3 Butantan utilizado nos pacientes durante o ensaio clínico. A contagem das células $\mathrm{CD}^{+}$permitiu avaliar o efeito do uso do produto na depleção dessa população celular responsável pela resposta celular de rejeição ao enxerto.

\section{RESULTADOS}

\section{1 - Pacientes: dados demográficos e esquema imunossupressor}

As características demográficas dos 25 pacientes estão descritas na Tabela 1. A maioria dos pacientes avaliados era do sexo feminino, de cor branca e com idade média de 34 anos. Glomerulonefrite Crônica foi a causa da insuficiência renal mais freqüentemente observada, e os pacientes encontravam-se em tratamento dialítico há pelo menos 5,6 anos. Com relação ao número de transfusões, apenas dois pacientes nunca haviam sido transfundidos e seis pacientes haviam recebido mais de dez transfusões antes do transplante.

Tabela 1. Dados gerais

\begin{tabular}{cc}
\hline Características & Número total $=\mathbf{2 5}$ pacientes \\
\hline Sexo & Fem $=16 /$ Masc $=9$ \\
Cor & Branco $=13 /$ Negro $=4 /$ Desc $=8$ \\
Idade média no Tx & 12 anos \\
Número de Tx & $1^{0} \mathrm{Tx}=17 / 2^{\circ} \mathrm{TX}=5 / 3^{\circ} \mathrm{Tx}=2 /$ Desc $=1$ \\
Doença de base & $\mathrm{GNC}=12 / \mathrm{NH}=5 / \mathrm{RVU}=2 / \mathrm{PNC}=1 /$ Desc $=5$ \\
$\mathrm{~N}^{0}$ transfusões pré-Tx & $0=2 / 1$ a $10=13 />10=6 /$ Desc $=4$ \\
Tipo de diálise (HD/DP) & $\mathrm{HD}=22 / \mathrm{DP}=3$ \\
Tempo médio de diálise (meses) & $75 \pm 42 \mathrm{~m}$ \\
Tipo de doador (vivo/cadáver) & $6 / 19$ \\
Tempo médio isquemia fria & $16 \mathrm{~h} \pm 11 \mathrm{~h}$ \\
Função retardada enxerto & $18(\mathrm{DV}=1 / \mathrm{DC} \mathrm{Cad}=17)$
\end{tabular}

Desc=desconhecido; TX=transplante; GNC=glomerulonefrite crônica; $\mathrm{NH}=$ nefropatia hipertensiva; $\mathrm{RVU}=$ refluxo vesico-ureteral;

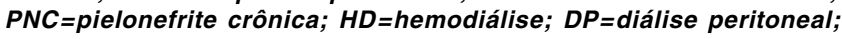
DV=doador vivo; Dcad=doador cadáver

Quanto ao número dos transplantes, 68\% dos pacientes recebeu o primeiro enxerto quando utilizou o anti-CD3. Foram 19 transplantes com doadores falecidos e seis transplantes com doador vivo, parente $(n=3)$ e não parente $(n=3)$. No transplante com doador falecido, o tempo médio de isquemia fria foi $16 \pm 11$ horas. Função retardada do enxerto, definida como necessidade de diálise na primeira semana após o transplante, foi observada em $72 \%$ dos pacientes, predominantemente nos pacientes que receberam o enxerto de doador cadáver.

O anti-CD3 Butantan foi utilizado como terapia de indução em nove pacientes e como tratamento de rejeição aguda em 16 pacientes. A duração média do uso do anti-CD3, tanto para profilaxia como para tratamento, foi nove dias $(\min =3$ dias e $\max =14$ dias), na dose de 5mg (uma ampola) ao dia. No grupo que recebeu anti-CD3 para tratamento de rejeição, três pacientes interromperam o uso do anti-CD3 no terceiro dia de tratamento. A interrupção deveu-se à perda do enxerto por rejeição grave ( $n=2$ pacientes) e mudança do diagnóstico de rejeição para pielonefrite aguda (um paciente).

O esquema imunossupressor de manutenção após o transplante foi predominantemente o esquema tríplice com azatioprina, prednisona e ciclosporina, utilizado por 20 pacientes. Em todos os pacientes, a administração de ciclosporina foi iniciada desde o primeiro dia de transplante. Dois pacientes receberam micofenolato mofetil, prednisona e ciclosporina/tacrolimus e um paciente, transplantado em 1995, recebeu esquema tríplice com ciclofosfamida em substituição à azatioprina. Dois pacientes usaram esquema duplo ou com azatioprina e prednisona $(n=1)$ ou com prednisona e ciclosporina $(n=1)$.

\section{2 - Uso profilático do anti-CD3}

Nove pacientes receberam anti-CD3 de forma profilática, com intuito de aumentar a imunossupressão inicial e prevenir a ocorrência de episódios de rejeição celular. Como mostra a Tabela 2, oito pacientes que receberam o anti-CD3 profilaticamente eram pacientes sensibilizados e com maior risco imunológico para ocorrência de rejeição. Em um paciente (paciente \#2), o uso do anti-CD3 foi apenas para avaliar a eficácia e segurança da medicação.

Tabela 2. Indicação para uso do anti-CD3 profilático

\begin{tabular}{cccc}
\hline Paciente \# & Indicação & N & Rejeição \\
\hline 16 & Retransplante & $n=1$ & não \\
7,23 & Retransplante+ Politransfusão & $n=2$ & sim/nao \\
4 & Retransplante+Prova cruzada pos contra Linf B & $n=1$ & sim \\
25,26 & Retransplante+Painel $>50 \%$ & $n=2$ & não/não \\
1,3 & Prova cruzada histórico positiva & $n=2$ & sim/não \\
2 & Avaliar eficácia da medicação & $n=1$ & não \\
\hline
\end{tabular}

Linf B=linfócitos B; Painel= reatividade contra um pool de antígenos HLA representativos de uma população

Dos nove pacientes que utilizaram o anti-CD3 profilaticamente, três pacientes (33\%) apresentaram um episódio de rejeição celular aguda (pacientes \# 1,4 e 7, Tabela 2). Em dois desses pacientes, o episódio de rejeição celular que se seguiu ao uso do anti-CD3 foi responsivo à terapia com metil-prednisolona e ambos os pacientes permaneceram com o enxerto funcionante no último seguimento de maio de 2006, com tempo de seguimento pós-transplante de nove e 13 anos. O paciente \#7, com antecedente de múltiplas transfusões no segundo transplante, desenvolveu episódio de rejeição vascular grave no $38^{\circ}$ dia e perdeu o enxerto renal 12,6 meses após o transplante.

Seis pacientes (67\%) não apresentaram rejeição celular após o uso profilático do anti-CD3 (Tabela 2). Desses pacientes, cinco tiveram boa evolução clínica e estão com o enxerto funcionante após tempo médio de $10 \pm 2$ anos após o transplante. $O$ valor médio da creatinina sérica no último seguimento (maio 2006) foi $1,9 \pm 1,4 \mathrm{mg} / \mathrm{dL}$. Um paciente (paciente \#16) perdeu o enxerto após 10,2 meses pós-transplante por recidiva de glomeruloesclerose segmentar e focal.

Em resumo, dos nove pacientes que receberam indução, dois perderam o enxerto e sete pacientes (78\%) apresentaram o enxerto em funcionamento no último seguimento em 2006. Nessa data, o tempo médio pós-transplante foi $8 \pm 4$ anos $(\min =3$ anos e máx $=$ 13 anos).

\section{3 - Uso terapêutico do anti-CD3}

Dezesseis pacientes receberam anti-CD3 para tratamento de rejeição. A escolha pelo uso do anti-CD3 ocorreu frente a diferentes condições clínicas e, por esta razão, distribuímos os pacientes em três grupos. O grupo 1 se compõe de 12 pacientes que tiveram 
o primeiro episódio de rejeição e utilizaram o anti-CD3 por não responderem à pulsoterapia com corticosteróide. No grupo 2 estão três pacientes que receberam anti-CD3 como escolha inicial para tratamento do primeiro episódio de rejeição. Diferentemente do grupo 1 , esses pacientes não receberam corticosteróide antes do anti-CD3. No grupo 3, com apenas um paciente, o anti-CD3 foi utilizado para tratamento do segundo episódio de rejeição. Por tratar-se de rejeição severa, o anti-CD3 foi utilizado como primeira escolha, sem uso prévio de corticosteróide.

Todos os pacientes estavam em seu primeiro transplante e a maioria recebeu o rim de doador falecido ( $88 \%$ dos pacientes). O esquema imunossupressor inicial era ciclosporina, azatioprina e prednisona, e nenhum paciente recebeu indução nos momentos iniciais do transplante. Os episódios de rejeição ocorreram no primeiro mês após o transplante em 14 pacientes. Dois pacientes tiveram rejeição no quinto mês após o transplante.

O diagnóstico histológico dos episódios de rejeição está representado na Tabela 3. Sete pacientes apresentaram rejeição celular grave (pacientes \# 9,10,11,13,14,19 e 22). Desses sete pacientes, seis tinham acometimento vascular associado, caracterizando uma rejeição de maior gravidade. $\mathrm{O}$ diagnóstico de rejeição celular de leve intensidade foi observado em dois pacientes do grupo 1 (paciente \#8) e um paciente do grupo 2 (paciente \#15). Um paciente apresentou rejeição hiperaguda tardia (paciente \#6). Os pacientes \#5, 12, 24 e 17 tiveram rejeição celular aguda diagnosticada por biópsia, mas a graduação histológica da rejeição não estava disponível no prontuário médico. O paciente \#21 recebeu tratamento com anti-CD3 por indicação clínica, mas a biópsia renal não confirmou o achado de rejeição.

$\mathrm{O}$ tratamento com anti-CD3 Butantan resultou em reversibilidade do quadro de rejeição em 11 pacientes (69\%). O critério utilizado para reversibilidade foi clínico, e se baseou na redução progressiva dos níveis de creatinina sérica. A evolução clínica dos 16 pacientes após o tratamento com anti-CD3 está detalhada na Tabela 3. Foram quatro perdas do enxerto precoce antes do sexto mês póstransplante, e cinco perdas do enxerto após 12 meses de transplante. Dos cinco pacientes que não reverteram o episódio de rejeição e perderam o enxerto, quatro retornaram ao programa de diálise e um paciente foi a óbito ainda durante o tratamento da rejeição. Um paciente foi a óbito no $17^{\circ}$ mês pós-transplante com o enxerto em funcionamento e um paciente não manteve seguimento ambulatorial no hospital de origem. Cinco pacientes que receberam anti-CD3 para tratamento de rejeição apresentaram o enxerto com boa função no último dia de seguimento (janeiro a março de 2006), com tempo de seguimento médio de $8,0 \pm 1,1$ anos.

\section{4 - Monitorização de células CD3+}

A monitorização de linfócitos $\mathrm{CD} 3+$ em algum momento do tratamento com anti-CD3 Butantan foi realizado em 18 pacientes, sendo cinco pacientes em uso profilático do anti-CD3 e 13 pacientes em uso terapêutico do anti-CD3. A contagem de células CD3+ foi realizada por citometria de fluxo e valores menores do que $30 \mathrm{cel} /$ $\mathrm{mm}^{3}$ foram considerados apropriados após depleção linfocitária com anti-CD3. No segundo dia de tratamento com anti-CD3, 15 pacientes tinham contagem de CD3 disponíveis para análise (Figura 1). Onze desses 15 pacientes tinham número de $\mathrm{CD} 3<30 \mathrm{cel} /$ $\mathrm{mm}^{3}$. É interessante notar que os quatro pacientes que não haviam apresentado queda dos valores de CD3 + abaixo de $30 \mathrm{cel} / \mathrm{mm}^{3}$ no segundo dia após o tratamento apresentaram queda dos valores para menos de $20 \mathrm{cel} / \mathrm{mm}^{3}$ no sétimo dia após início do anti-CD3. Os valores de CD3 maiores que $30 \mathrm{cel} / \mathrm{mm}^{3}$ foram registros pontuais de diferentes pacientes e não houve qualquer paciente que tenha tido contagem persistentemente acima de $30 \mathrm{cel} / \mathrm{mm}^{3}$.

Tabela 3. Achados histológicos dos episódios de rejeição e evolução clínica após tratamento com anti-CD3 (baseado na intenção de tratamento)

\begin{tabular}{|c|c|c|c|c|}
\hline \multicolumn{2}{|c|}{ Grupos Paciente $\left(n^{\circ}\right)$} & \multirow{2}{*}{$\frac{\text { Histologia da rejeição tratada com anti-CD3 * }}{\text { RCA }}$} & \multirow{2}{*}{$\frac{\text { Reversão da rejeição \# }}{\text { Sim }}$} & \multirow{2}{*}{$\begin{array}{c}\text { Situação Atual \#\# (meses pós-TX) } \\
\text { Perda: NCT (31m) }\end{array}$} \\
\hline \multirow{12}{*}{ G1 } & 5 & & & \\
\hline & 6 & Rejeição hiperaguda tardia & Não & Perda: rejeição hiperaguda (7d) \\
\hline & 8 & RCA leve & Sim & Perda: NCT (77m) \\
\hline & 9 & RCA severa+ NTA & Não & Perda: rejeição severa (17d) \\
\hline & 10 & Rejeição aguda vascular + NTA & Não & Perda: NCT (14m) \\
\hline & 11 & Rejeição aguda vascular & Não & Perda: rejeição aguda vascular + óbito (5m) \\
\hline & 12 & $\mathrm{RCA}+\mathrm{NTA}$ & $\operatorname{Sim}$ & $\mathrm{SCr}=1,27 \mathrm{mg} / \mathrm{dL}(106 \mathrm{~m})$ \\
\hline & 19 & Rejeição aguda vascular & $\operatorname{Sim}$ & Óbito com rim em funcionamento (17m) \\
\hline & 20 & RCA leve & $\operatorname{Sim}$ & Perda: NCT (15m) \\
\hline & 21 & Pielonefrite + NTA & Sim & $\mathrm{SCr}=1,55 \mathrm{mg} / \mathrm{dL}(98 \mathrm{~m})$ \\
\hline & 22 & Rejeição aguda vascular + NTA & $\operatorname{Sim}$ & $\mathrm{SCr}=1,4 \mathrm{mg} / \mathrm{dL}(8 \mathrm{~m})$ \\
\hline & 24 & $\mathrm{RCA}$ & $\operatorname{Sim}$ & perda seguimento \\
\hline \multirow{3}{*}{ G2 } & 14 & Rejeição aguda vascular + NTA & Sim & $\mathrm{SCr}=1,1 \mathrm{mg} / \mathrm{dL}(103 \mathrm{~m})$ \\
\hline & 15 & RCA leve + NTA & Sim & $\mathrm{SCr}=1,0 \mathrm{mg} / \mathrm{dL}(103 \mathrm{~m})$ \\
\hline & 17 & RCA+NTA+Pielonefrite aguda & $\operatorname{Sim}$ & Perda: NCT (21m) \\
\hline G3 & 13 & Rejeição aguda vascular & Não & Perda: rejeição severa (2m) \\
\hline \multicolumn{5}{|c|}{$\begin{array}{l}\text { G1= Primeiro episódio rejeição córtico-resistente; G2= Primeiro episódio rejeição com anti-CD3 como primeira escolha; G3= Segundo episódio re- } \\
\text { jeição com anti-CD3 como primeira escolha }\end{array}$} \\
\hline \multicolumn{5}{|c|}{$R C A=$ rejeição celular aguda; NTA=necrose tubular aguda; $S C r=$ creatinina sérica; $N C T=$ nefropatia crônica do transplante } \\
\hline
\end{tabular}


Figura 1 - Contagem de células CD3 após o uso de anti-CD3 Butantan

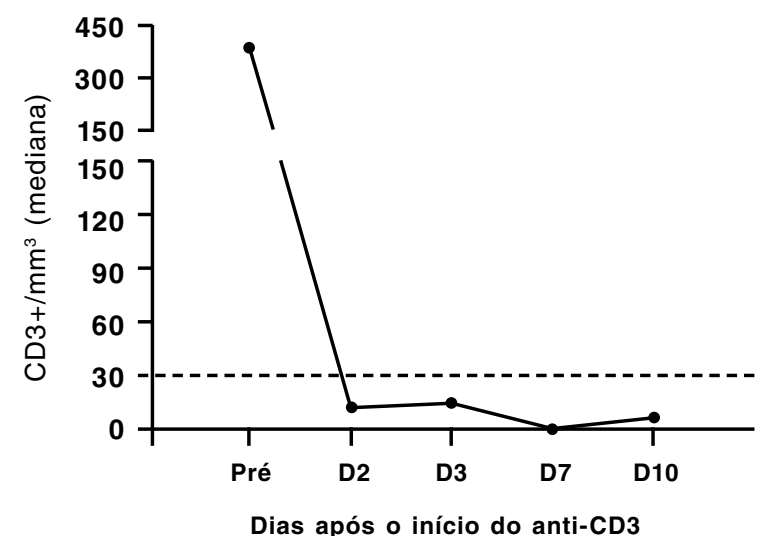

$$
\begin{aligned}
& \text { Valor mediano } \\
& \text { (min - máx) }
\end{aligned}
$$

$\begin{array}{ccccc}370 & 13 & 14 & 1 & 6 \\ (26-1790) & (0-76) & (0-428) & (0-199) & (0-64)\end{array}$

$\%$ pacientes com

$\mathrm{CD} 3+<30 \mathrm{cels} / \mathrm{mm}^{3}$

$75 \%$

$93 \%$

$92 \%$

\section{5 - Eventos adversos}

Os eventos adversos ocorridos durante o tratamento com anti-CD3 estão listados na Tabela 4 . O evento adverso mais freqüentemente observado foi febre, tendo ocorrido em $68 \%$ dos pacientes. Alterações cardiovasculares foram relatadas por sete pacientes, com seis pacientes apresentando hipotensão arterial e um paciente com taquicardia. Das alterações neurológicas, foram observados quatro casos de convulsão durante o tratamento com o anti-CD3, sendo que um paciente apresentou convulsão em vigência de quadro de meningite bacteriana. Diarréia e náuseas foram relatadas por cinco e três pacientes, respectivamente. Dor abdominal e/ou aumento de amilase sérica ocorreu em dois pacientes.

Tabela 4. Eventos adversos durante o uso do anti-CD3

\begin{tabular}{cc}
\hline Eventos adversos & N pacientes (\%) \\
\hline Febre & $17(68 \%)$ \\
Hipotensão arterial & $6(24 \%)$ \\
Taquicardia & $1(4 \%)$ \\
Convulsão & $4(16 \%) \dagger$ \\
Cefaléia & $3(12 \%)$ \\
Sonolência & $1(4 \%)$ \\
Mialgia/artralgia & $1(4 \%)$ \\
Diarréia & $5(20 \%)$ \\
Náuseas ou vômitos & $3(12 \%)$ \\
Dor abdominal e/ou † amilase & $2(8 \%)$ \\
\hline
\end{tabular}

† Um paciente teve diagnóstico de meningite bacteriana durante $o$ tratamento com o anti-CD3

A ocorrência de infecção e tumores nos pacientes que receberam anti-CD3 foi avaliada retrospectivamente nos prontuários médicos. No total, 23 pacientes tinham prontuário satisfatoriamente informativo sobre essas questões. Não houve relato de doença linfoproliferativa ou qualquer outro tipo de tumor nos pacientes avaliados. Para investigar o impacto do uso do anti-CD3 na ocorrência de infecção, consideramos os episódios de infecção nos seis meses imediatamente após o uso do anti-CD3 como evento adverso relacionado ao uso da droga. Como mostra a Figura 2, nos primeiros seis meses após uso do anti-CD3, foi observada infecção bacteriana em $56 \%$ dos pacientes, mais comumente infecção urinária. Foi observado um caso de meningite bacteriana. Infecções virais ocorreram em $43 \%$ dos pacientes, principalmente por citomegalovírus e/ou herpes vírus. Infecção fúngica por cândida ocorreu em um paciente. Todos os episódios de infecção que ocorreram nos seis meses após uso do anti-CD3 responderam adequadamente ao tratamento antimicrobiano específico. Um paciente apresentou infecção tardia pelo citomegalovírus, 17 meses após o transplante, e evoluiu com infecção respiratória grave e óbito.

Figura 2 - Infecção em pacientes transplantados renais que utilizaram

\begin{tabular}{|c|c|}
\hline 1 - INFECÇÃO VI[ & $\begin{array}{l}\text { Herpes simples } / \text { zooster }=4 \\
\mathrm{CMV}=4\end{array}$ \\
\hline \multirow[t]{3}{*}{$\mathrm{n}=10 \operatorname{cas} 0 \mathrm{~s}(43 \%)$} & Herpes + CMV $=1$ \\
\hline & Infec. Viral não especificada =1 \\
\hline & Infecção respiratória = 2 \\
\hline \multirow{4}{*}{$\begin{array}{l}\text { 2- INFECÇÃO BACTERIANA } \\
n=13 \text { casos }(56 \%)\end{array}$} & Infecção urinária = 8 \\
\hline & Infecção ferida operatória = 2 \\
\hline & Bacteremia = 1 \\
\hline & Meningite $=1$ \\
\hline 3 - INFECÇÃO FÚNGICA & Vlíase oral = \\
\hline$=1$ cas 0 & mase vial-1 \\
\hline
\end{tabular}
anti-CD3 Butantan

\section{DISCUSSÃO}

O presente estudo mostra a experiência da utilização do anti-CD3 Butantan na profilaxia e tratamento de episódios de rejeição aguda em pacientes transplantados renais. Observamos que o anti-CD3 Butantan reduziu a população de linfócitos CD3 de forma eficaz, mostrando-se benéfico na profilaxia e tratamento de rejeições graves com tolerabilidade satisfatória.

A indicação do uso profilático do anti-CD3 em nossos pacientes foi predominantemente pelo perfil de maior risco imunológico para a ocorrência de rejeição. Tratava-se de pacientes hipersensibilizados ou candidatos à re-transplante. Apenas um paciente recebeu antiCD3 Butantan com intuito apenas de avaliar a eficácia da medicação. A ocorrência de rejeição aguda após o uso profilático foi de $33 \%$ se considerarmos os nove pacientes, e 37,5\% se considerarmos apenas os oito pacientes de maior risco imunológico. Este é um percentual muito semelhante ao observado em 44 pacientes transplantados renais no Hospital das Clínicas da FMUSP entre os anos de 1995 e 2001 e que utilizaram o anti-CD3 orthoclone-OKT3 (Ortho Biotech) profilaticamente. Nesse grupo de pacientes, a incidência de rejeição aguda foi de $36 \%$ para os receptores de doador falecido e $33 \%$ para os receptores de doador vivo..$^{13}$ Quando comparado aos estudos internacionais do início dos anos 90, o percentual de pacientes do presente estudo que apresentou rejeição aguda é ainda menor. ${ }^{14,15}$ Em estudo prospectivo, 207 pacientes transplantados renais foram avaliados quanto à ocorrência de rejeição aguda com a utilização profilática do anti-CD3 comercial OKT3.${ }^{14} \mathrm{O}$ grupo que recebeu OKT3 como indução e esquema tríplice (azatioprina, prednisona e ciclosporina) apresentou $51 \%$ de rejeição aguda. Os autores observaram que o uso profilático diminuiu significativamente a ocorrência de rejeição aguda comparada ao grupo controle, que 
só recebeu esquema tríplice e teve $66 \%$ de rejeição. ${ }^{14}$ Assim como relatado neste estudo, observamos que os episódios de rejeição que se seguiram ao uso profilático do anti-CD3 respondem, em sua maioria, ao tratamento com corticóide. Em nosso estudo, apenas um paciente teve episódio de rejeição vascular grave e perdeu o enxerto 11 meses após a rejeição. A sobrevida do enxerto foi satisfatória. Dos nove pacientes que receberam anti-CD3 Butantan profilaticamente, $78 \%$ apresentaram o rim em funcionamento no último seguimento, que variou de três a 13 anos.

O uso terapêutico do anti-CD3 reverteu 69\% dos episódios de rejeição aguda ocorrida em 16 pacientes. Cinco pacientes não responderam ao tratamento com anti-CD3, e na maior parte dos casos, evoluíram com perda do enxerto poucos dias após o diagnóstico da rejeição. Os episódios eram córticoresistentes em sua maioria, com infiltrado celular importante e acometimento vascular à biópsia. Em um desses cinco pacientes, a histologia mostrava quadro de rejeição hiperaguda tardia, que é conhecidamente um processo de rejeição mediada por anticorpo. Portanto, é possível que alguns desses casos não tenham respondido ao tratamento com anti-CD3 porque o mecanismo imunológico predominantemente envolvido na rejeição não tenha sido o componente celular, e sim o componente humoral. $\mathrm{O}$ anticorpo anti-CD3, assim como as globulinas anti-linfocíticas exercem sua ação no tratamento da rejeição através da eliminação de células $\mathrm{CD} 3$, com baixa eficácia no tratamento das rejeições de caráter humoral. ${ }^{16}$

Dois pacientes que apresentaram episódios de rejeição aguda, considerados revertidos após a utilização do anti-CD3, evoluíram com nefropatia crônica do enxerto em menos de 24 meses após o transplante. Nesses casos, é possível que a resposta imune ao enxerto tenha persistido de forma agressiva, mesmo após a depleção linfocitária induzida pelo anti-CD3. É importante notar que a análise de reversibilidade dos episódios de rejeição após o tratamento com anti-CD3 foi baseada na evolução dos níveis de creatinina sérica, o que pode representar uma limitação diagnóstica. Como não foi realizada biópsia após tratamento, esta avaliação clínica não pode assegurar que o infiltrado celular tenha desaparecido completamente.

Na prática clínica, o tratamento da rejeição aguda, especialmente dos episódios resistentes ao corticóide, é realizado com anticorpos policlonais ou monoclonais, como o anti-CD3. Recentemente, uma meta-análise com 49 estudos clínicos realizados entre os anos de 1979 a 2003 não observou diferença na evolução dos enxertos tratados com anticorpos mono ou policlonais. Os eventos de falência da reversibilidade da rejeição, recorrência de rejeição e perda do enxerto foi semelhante entre os diferentes tipos de anticorpos utilizados, assim como foram semelhantes o risco de morte, malignidade, infecção como causa de morte e infecção por CMV entre as diferentes preparações. ${ }^{17}$ No entanto, a ocorrência de eventos adversos relacionados à infusão das preparações foi diferente, sendo o anticorpo anti-CD3 mais freqüentemente associado a eventos como febre e tremores. ${ }^{17} \mathrm{Em}$ nosso estudo, febre também foi o sintoma mais freqüentemente relatado durante a infusão do anti-CD3, referido por $68 \%$ dos pacientes. Outros eventos, como hipotensão arterial, diarréia e convulsão também foram observados em nossos pacientes e foram semelhantes aos relatados com a administração de outras preparações comerciais. ${ }^{18,19}$
Uma das limitações dos estudos com anticorpos anti-linfocitários é a falta de informação sobre os efeitos deletérios destas medicações na morbidade e mortalidade dos pacientes. ${ }^{17}$ Sabe-se que estas medicações aumentam o risco de infecção e tumores, principalmente infecções virais pelo CMV e doença linfoproliferativa pós-transplante. ${ }^{20} \mathrm{Em}$ nosso estudo, nem todos os pacientes avaliados tinham informações disponíveis sobre infecção nos seis meses seguintes ao uso do anti-CD3. Dos 23 pacientes com informação, 56\% apresentaram infecção bacteriana e $43 \%$ apresentaram infecção viral, principalmente pelo CMV. Nenhum caso de malignidade foi observado em nosso meio, mostrando uma boa tolerância à medicação utilizada.

É preciso comentar que o presente estudo possui limitações, principalmente por se tratar de estudo retrospectivo. A busca de dados em prontuário médico, de forma retrospectiva, em um número limitado de pacientes é uma destas limitações. Vale também ressaltar que na maior parte dos casos, a utilização da preparação anti-CD3 Butantan se deu entre os anos de 1993 a 1998, época em que o esquema imunossupressor clássico era prednisona, ciclosporina e azatioprina. Nos dias atuais, o esquema imunossupressor foi modificado, com a introdução do micofenolato mofetil/sódico e do tacrolimus. O esquema imunossupressor atual reduziu significativamente a taxa de rejeição aguda, embora não tenha reduzido na mesma proporção a ocorrência de nefropatia crônica do enxerto. Por outro lado, é interessante notar que o perfil dos pacientes transplantados também parece ter modificado ao longo destes últimos anos. Como pudemos observar em nosso estudo, era grande o número de pacientes politransfundidos, o que caracterizava uma população de maior risco para desenvolver episódios de rejeição. Portanto, faz-se necessária a realização de um estudo prospectivo no qual o anti-CD3 Butantan seja avaliado no cenário da imunossupressão atual.

O anticorpo monoclonal anti-CD3 comercialmente disponível no País e incluso na lista de importações do Ministério de Saúde é o produto muromonab - CD3, orthoclone OKT3. No momento, a principal utilização do anti-CD3 tem sido no tratamento dos episódios de rejeição aguda de caráter celular, não responsivos à corticoterapia. Como profilaxia, muitos centros têm optado pela utilização do anticorpo anti-receptor de IL-2 em pacientes de menor risco imunológico ou preparações policlonais, como a timoglobulina, em pacientes de alto risco imunológico. Essa preferência ocorre pela menor incidência de feitos colaterais, no caso do anti-receptor de IL-2, ou pela possibilidade de bloquear a ação de outras moléculas que não somente células $\mathrm{CD} 3$, no caso da timoglobulina.

O Instituto Butantan mantém a produção de anti-CD3 e planeja, juntamente com os vários centros transplantadores do país, iniciar em futuro próximo um estudo prospectivo e controlado que avalie a utilização do anti-CD3 Butantan no tratamento dos episódios de rejeição aguda de caráter celular.

\section{CONCLUSÃO}

Concluímos que o anti-CD3 Butantan reduziu a população de linfócitos CD3 de forma eficaz, mostrando-se benéfico na profilaxia e tratamento de rejeições graves com tolerabilidade 
satisfatória. Esta experiência inicial favorável fundamenta a realização de outros estudos clínicos prospectivos com número maior de pacientes. A utilização de uma preparação inteiramente desenvolvida em nosso país poderá reduzir o custo do tratamento imunossupressor e fomentar o crescimento da área de biotecnologia nacional.

\section{AGRADECIMENTOS}

Os autores agradecem a valiosa contribuição da farmacêutica Ivone Yamaguchi e da Diretora de Produção Hisako Higashi, fundamentais para o envase e controle de qualidade do anti-CD3. Agradecemos também a contribuição da Dra. Kikumi Ozaki e da Dra Elizete Keitel na revisão dos prontuários médicos.

\section{ABSTRACT}

Purposes: The monoclonal anti-CD3 antibody has been used as induction and to treat acute rejection episodes in organ transplantation. This retrospective study reports a trial in three Brazilian transplantation centers, which have used a national anti-CD3 preparation developed by the Butantan Institute (São Paulo, Brazil), in renal transplant patients. Methods: Twenty-five patients have used anti-CD3 as induction therapy $(n=9)$ or to treat acute rejection $(n=16)$. Results: Most patients $(89 \%)$ using anti-CD3 for induction were sensitized, and $33 \%$ of cases experienced acute rejection. The therapeutic use was indicated to treat cortical-resistant rejection or episodes of major histological severity, and it promoted the clinical reversion in $69 \%$ of cases. In the majority of patients, the use of the Butantan CD3 reduced the amount of $\mathrm{CD} 3+$ cells to lower than 30cells $/ \mathrm{mm}^{3}$ at the second treatment day. Most frequent adverse event was fever, and bacterial and viral infections in 13 and 10 patients, respectively. Up to the middle of the 8 follow-up years, no tumor case was reported. Conclusion: Concluding, the use of Butantan anti-CD3 has shown effectiveness in preventing and to treat acute rejection in renal transplantation.

Keywords: Muromonab-CD3, Kidney Transplantation, Immunosuppressant, Graft Rejection.

\section{REFERÊNCIAS}

1. Kohler G, Milstein C. Continuous cultures of fused cells secreting antibody of predefined specificity. Nature 1975;256:495-7.

2. Woodle ES, Xu D, Zivin RA, Auger J, Charette J, O'Laughlin R, et al. Phase I trial of a humanized, Fc receptor nonbinding OKT3 antibody, huOKT3gamma1(Ala-Ala) in the treatment of acute renal allograft rejection. Transplantation 1999;68:608-16.

3. Monteiro FAS, Panajotopoulos N, Aparecida RM, Ianhez LE, Macelino JR, Stephano MA, et al. Desenvolvimento da globulina anti-timocitária butancor e sua aplicação clínica no transplante renal. Jornal Brasileiro de Transplantes 1999;2:3-8.

4. Moro AM, Rodrigues MT, Gouvea MN, Silvestri ML, Kalil JE, Raw I. Multiparametric analyses of hybridoma growth on glass cylinders in a packed-bed bioreactor system with internal aeration. Serum-supplemented and serum-free media comparison for MAb production. J Immunol Methods 1994;176:67-77.

5. Rodrigues MTA. Produção e Controle de Qualidade do Anticorpo Monoclonal AntiCD3 para Uso Terapêutico [tese]. São Paulo: Faculdade de Ciências Farmacêuticas - Universidade de São Paulo; 1996.

6. CPMP. Committee for Proprietary Medicinal Products - Guidelines on the production and quality control of monoclonal antibodies of murine origin intended for use in man. Trends Biotechnol 1988;6:G5-G8.

7. WHO. World Health Organization - Expert Committee on Biological Standardization. Guidelines for assuring the quality of monoclonal antibodies for use in humans. Technical Report Series 1992;822:47-67.

8. FDA. Office of Biologics Research and Review. Points to consider in the manufacture and testing of monoclonal antibody products for human use, 1987:1-18.

9. FDA. Points to consider in the manufacture and testing of monoclonal antibody products for human use. Rockville., 1994:1-21.

10. Rodrigues MTA, Raw I, Moro AM. Residual DNA from Hybridoma Cultures: Decorrence of apoptosis? I. In: Carrondo MJT, Griffiths B, Moreira JLP, eds. Animal Cell Technology: From Vaccines to Genetic Medicine: Dordrecht: Kluwer Academic Publishers, 1997:467-72.
11. WHO. World Health Organization - Requirements for the use of animal cells as in vitro substrates for the production of biologicals. Technical Report Series 1998;878:19-52.

12. Boyum A. Separation of blood leucocytes, granulocytes and lymphocytes. Tissue Antigens 1974;4:269-74.

13. Castro MC, Araujo LM, Nahas WC, Arap S, David-Neto E, Ianhez LE. Induction versus noninduction therapy in kidney transplantation: considering different PRA levels and different induction therapies. Transplant Proc 2004;36:874-6.

14. Norman DJ, Kahana L, Stuart FP, Jr., Thistlethwaite JR, Jr., Shield CF, 3rd, Monaco Aet al. A randomized clinical trial of induction therapy with OKT3 in kidney transplantation. Transplantation 1993;55:44-50.

15. Frey DJ, Matas AJ, Gillingham KJ, Canafax D, Payne WD, Dunn DL, et al. Sequential therapy--a prospective randomized trial of MALG versus OKT3 for prophylactic immunosuppression in cadaver renal allograft recipients. Transplantation 1992;54:50-6.

16. Casadei DH, del CRM, Opelz G, Golberg JC, Argento JA, Greco G, et al. A randomized and prospective study comparing treatment with high-dose intravenous immunoglobulin with monoclonal antibodies for rescue of kidney grafts with steroidresistant rejection. Transplantation 2001;71:53-8.

17. Webster AC, Pankhurst T, Rinaldi F, Chapman JR, Craig JC. Monoclonal and polyclonal antibody therapy for treating acute rejection in kidney transplant recipients: a systematic review of randomized trial data. Transplantation 2006;81:953-65.

18. A randomized clinical trial of OKT3 monoclonal antibody for acute rejection of cadaveric renal transplants. Ortho Multicenter Transplant Study Group. N Engl J Med 1985;313:337-42.

19. Goldman M, Abramowicz D, De Pauw L, Alegre ML, Widera I, Vereerstraeten P, et al. OKT3-induced cytokine release attenuation by high-dose methylprednisolone. Lancet 1989;2:802-3.

20. Rubin RH, Tolkoff-Rubin NE. The impact of infection on the outcome of transplantation. Transplant Proc 1991;23:2068-74. 